\title{
Semantic Priming Effects on the Lexical Switching Task in Children with and without Speech Sound Disorders
}

\author{
Da-Hee $\mathrm{Oh}^{\mathrm{a}}$, Ji-Wan $\mathrm{Ha}^{\mathrm{b}}$ \\ ${ }^{a}$ Department of Rehabilitation Science, Graduate School of Daegu University, Gyeongsan, Korea \\ ${ }^{b}$ Department of Speech Pathology, Daegu University, Gyeongsan, Korea
}

Correspondence: Ji-Wan $\mathrm{Ha}, \mathrm{PhD}$ Department of Speech Pathology, Daegu University, 201 Daegudae-ro, Jillyang-eup, Gyeongsan 38453, Korea

Tel: $+82-53-850-4327$

Fax: $+82-53-850-4329$

E-mail: jw-ha@daegu.ac.kr

Received: July 14, 2020

Revised: August 8, 2020

Accepted: August 8, 2020

This research was supported by Daegu University Research Grant, 2019.

\begin{abstract}
Objectives: The purpose of this study was to investigate the bi-directions between long distance stages by comparing the semantic priming effect on children with and without speech sound disorders. Methods: The study subjects were 15 typically developing peers (TD group), 15 children with pure speech sound disorders (pure SSD group) and 10 children with speech sound disorders with language disorder (SSD+LD group) from 3 to 5 years of age. The lexical switching task consisted of naming two pictures. A context picture (priming stimulus) was sometimes replaced with a target picture (target stimulus); the picture names were related or unrelated in meaning. The authors measured response time, response accuracy, and error type rates. Results: The response time was not significantly different between the pure SSD group and the TD group in semantic conditions. However, response accuracy was significantly different between the pure SSD group and the TD group. The response accuracy of the SSD+LD group was not significantly different between semantic and non-semantic conditions. As a result of the error analysis, the SSD+LD group showed significantly more 'formal' errors than the pure SSD group, whereas the pure SSD group showed significantly more 'unrelated' errors than the SSD+LD group. Conclusion: This study demonstrated that bi-directional interaction of each stage decayed semantic priming effect. The findings suggest that studies on communication disorders should be conducted comprehensively in a broad range of areas, not in specific areas.
\end{abstract}

Keywords: Speech sound disorder, Semantic priming effect, Long distance interactive effect
언어심리학자들은 구어산출과정에서 한 하위단계가 다른 하위 단계에 어떠한 영향을 미치는지에 대해 고민해왔다. 이에 대한 일 반적인 통념은 구어산출을 위한 각 단계는 계열적(serial)이기 때문 에 상위 수준의 단계가 인접한 단계에 한해 하향적(top-down)으로 영향을 미친다는 것이다(Levelt, Roelofs, \& Mayer, 1999). 다시 말 해, 전언어단계(pre-verbal stage), 어휘단계(lexical stage), 하위어휘 단계(sublexical stage), 운동단계(motor stage)가 순차적으로 개시 되어 이전 단계가 이후 단계에 영향을 미칠 수 있으나, 그 반대의 가 정은 성립하지 않는다는 것을 의미한다. 그러나 이러한 주장은 연 결주의(connectionism)에서 상당한 논쟁을 불러일으켰다. 연결주 의를 지지하는 학자들은 전언어, 어휘, 하위어휘, 운동단계의 구분
을 수용하면서도, 동시에 구어산출이 단순히 일방향적인 계열적 처리로만 이루어진다는 것은 부정하였다(Cutting \& Ferreira, 1999; Dell, 1986; Peterson \& Savoy, 1998). 이들은 시간적 순서(temporal sequence)는 산출의 본질적 특성이지만, 그것은 계열적이지 않고 연쇄적(cascading)으로 발생한다고 명시하였다(Dell, Chang, \& Griffin, 1999). 이것은 연결주의 모형의 가장 매력적인 기제로, 이전 단계가 완료되기 전 이미 이후 단계가 활성화되어 각 단계 간 하향 적 및 상향적(bottom-up) 처리가 동시에 발생한다는 것이다.

대표적인 연결주의 학자인 Dell 등(1999)은 구어산출단계 간 양 방향의 상호작용 개념을 의사소통과정에서 나타나는 말 오류와 연 관 지어 설명하였다. 그는 특정 단계의 붕괴가 해당 프로세스의 오 
류로만 끝나지 않고 인접한 단계들에 연쇄적인 붕괴를 초래하여 다 양한 오류로 나타난다고 제안하였다. 대단히 흥미로운 가설이긴 하 나, 어휘단계와 하위어휘단계와 같이 인접 단계 간 상호작용을 전 제로 한 것이기에, 이 개념을 전체 구어처리과정에 적용하여 의사 소통의 붕괴를 설명하는 것은 매우 어려운 주제이다. 그러나 최신 의 연구는 양방향의 상호작용이 인접하지 않은 단계 간에도 유효 하다고 제안하였는데(Fink, Oppenheim, \& Goldrick, 2017; Goldrick et al., 2019; Heisler, Goffman, \& Younger, 2010; Kim \& Ha, 2018), 이를 ‘비인접 단계의 상호작용 효과(long distance interactive effect)'라 한다. 이들은 구어산출단계의 연쇄적 활성화로 인해 각 단계의 활성화 동안 시간적 중첩(temporal overlap)이 발생한다 고 언급하였다(Fink et al., 2017). 따라서 중첩된 시간 내에서 여러 네트워크가 동시활성화(co-activation)될 때, 인접하지 않은 단계, 예를 들어 전언어단계와 운동단계 간에도, 간접적 영향을 주고받 을 수 있다는 것이다. 이는 구어산출과정에서 발생하는 조음의 오 류에 대해 시사하는 바가 있으며, 특히 조음부 자체에 결함을 가진 말소리장애(speech sound disorder, SSD) 아동의 경우에는 더욱 그 러하다. 비인접 단계의 상호작용이 실제한다면, 전언어단계인 의미 처리 혹은 어휘단계인 어휘접근의 방해가 연쇄적인 붕괴를 초래하 여 최하단에 위치한 조음부에까지 부정적인 영향을 미칠 수 있고, 이것은 조음산출의 변이성, 조음실행 시간의 연장과 같은 결함으 로 연결될 수 있기 때문이다(Kim \& Ha, 2018).

비인접 단계의 상호작용을 포함하여 구어산출과정에서 일어나 는 다양한 영향들을 증명하고자 한 논문들 가운데에는 운동단계 인 조음부에 초점을 둔 연구가 다수 있다(Fink et al., 2017; Goldrick et al., 2019; Heisler et al., 2010). 이는 조음부가 구어산출모형 의 최하단에 위치하기 때문에 이전 단계들의 순차적 영향의 결과 물로 설명하기에 용이하고, 표면적으로 관찰이 가능하다는 조음부 자체의 특성에 기인한 것일 수 있다. 그러나 조음부와 여타 상위처 리단계와의 관계를 분석한 대부분의 연구들은 상위처리단계 중 주 로 어휘단계 또는 하위어휘단계에 치중하고 있으며(Fink et al., 2017; Goldrick et al., 2019; Heisler et al., 2010), 조음부에서 가장 멀 리 떨어져 있는 전언어단계인 개념화부에 대한 것은 찾아보기 어렵 다. 그러나 조음부 또한 구어산출의 가장 상위단계인 개념화부의 영향권 안에 있음을 고려할 때, 개념화부가 조음부에 미칠 간접적 영향에 대해 궁금하지 않을 수 없다. 또한 SSD 아동의 경우 개념화 부는 상대적으로 보존하고 있을 가능성이 크기 때문에, 구어산출 과정에서 이 단계의 일시적 방해 또는 활성화가 조음부에 미치는 영향에 대해 살펴보는 것은 중재활동 시 이들의 강점을 활용하는 방안에 대해 시사하는 바가 있을 것이다.
구어산출과정에서 한 가지 더 염두에 두어야 할 점은 연속구어 는 하나의 어휘로만 구성되어 있는 것이 아니라, 여러 어휘들이 전 체 발화의 관계 안에서 서로 연결되어 있다는 것이다. 이 경우 한 어 휘 내에서 각 하위단계 간 상호작용뿐 아니라 인접한 어휘들 각각 의 하위단계들 간 총체적 영향을 고려해야 할 것이다. 예를 들어 '야 채와 가지’와 ‘바지와 가지’라는 발화에서 두 어휘 간 전자는 의미정 보를, 후자는 음운정보를 공유하기 때문에, 앞에 위치한 어휘에서 활성화된 의미정보 또는 음운정보는 뒤에 오는 어휘의 의미처리 또 는 음운처리를 촉진하거나 방해할 가능성이 있다. 그러나 이러한 가능성을 인정한다 하더라도, 구어산출과정에서 발생하는 오류의 시발점을 규정하는 것, 예를 들어 ‘바지와 가지’에서/가지/를 [바지] 라고 잘못 발음한 것이 음운이나 조음 그 자체의 결함인지, 혹은 해 당 어휘 '가지' 내에서 다른 하위단계에서 발생한 방해에 기인한 것 인지, 혹은 인접한 어휘 ‘바지’의 특정 하위단계에서의 방해에 기인 한 것인지, 이 모든 경우의 수를 헤아리는 것은 불가능해 보인다. 이 때 다행스러운 것은 주의가 분산된 상태에서의 인간의 단기기억 보 유량은 그리 길지 않다는 것이다. 즉, 연속구어산출 시 새로운 정보 에 주의를 할당하는 순간 이전에 활성화된 정보는 빠른 속도로 사 라지게 되어 있다. 이 가운데 음운정보의 보유 시간은 매우 짧은 반 면, 의미정보는 상대적으로 오랫동안 잔존하는 것으로 보고되었다 (Bloem, Van den Boogaard, \& La Heij, 2004).

이처럼 인접 어휘 간 상호작용에 있어 시간 간격은 매우 중요한 변수로, 짧은 시간 내에 연속적으로 발화하게 되면 인접 어휘들 간 영향을 배제할 수 없다. 일상생활에서 짧은 시간 내에 연속적으로 어휘를 산출하거나 떠올리는 경우로는, 잘못 인출한 어휘에 대해 그 오류를 빠르게 감지하여 다른 어휘로 수정할 때의 상황을 생각 해 볼 수 있다. 때로는 산출 동안 오류를 깨닫고 그 어휘를 미처 다 발음하기도 전에 다른 어휘로 바꾸어 말하기도 한다. 이는 무척 짧 은 시간 내에 일어나는 일로, 이때 먼저 활성화된 오류 어휘와 나중 에 활성화된 수정 어휘의 상호작용 가능성은 상당히 높아 보이며, 이 과정에서 특히 오류 어휘의 의미정보는 비교적 오랫동안 잔존하 여 수정 어휘의 의미처리 이후 과정에 영향을 줄 것으로 보인다. 발 화를 산출하는 동안 본인의 발화에 대해 스스로 모니터링하고 오 류가 감지되면 이를 재빠르게 수정하는 행동은 일상생활에서 흔히 관찰되는 의사소통활동 중 하나이다. 이러한 점을 감안할 때, 짧은 시간 간격의 인접 어휘들 간 관계를 파악하는 것은 일상 발화에서 흔히 발생하는 오류 수정의 성공 또는 실패에 대해 시사하는 바가 있을 것이다.

이상과 같이 살펴본 어휘 내 비인접 단계의 상호작용 효과, 그리 고 빠른 시간 안에 연속 산출되는 인접 어휘 간 영향은 심리언어학 
분야에서 뜨거운 이슈이긴 하나, 이를 의사소통장애 분야에 적용 한 연구는 미비한 실정이다. 본 연구에서는 구어처리과정의 양방향 적인 상호작용이 비인접 단계 간에도 일어나는지 알아보기 위해, 구어산출의 최하단인 조음부에 결함이 있는 SSD 아동을 대상으 로 최상단인 개념화부를 촉진했을 때 나타나는 어휘산출의 양상 을 살펴보고자 하였다. 인접한 두 어휘 간 영향을 이용하여 개념화 부에 일시적으로 촉구를 가할 수 있는 대표적인 실험방법으로 '의 미점화(semantic priming)' 과제가 있다.

의미적으로 관련 있는 점화자극이 표적자극에 대해 점화효과 (priming effect)를 야기한다는 것은 이미 잘 알려져 있는 사실이다. 그러나 이것이 정적 점화효과인지 부적 점화효과인지에 대해서는 의견이 분분하다. 분명한 것은 자극의 유형과 자극 간 시간 간격에 따라 점화효과는 정반대로 나타난다는 것이다(Alario, Segui, \& Ferrand, 2000; Bloem et al., 2004; Hartsuiker, Pickering, \& de Jong, 2005). Bloem 등(2004)에 따르면 개념(의미)을 공유하는 점화 자극은 활성화 확산(spreading activation)을 통해 표적자극을 빠 르게 어휘화 시킨다(예, 과일-사과). 반면 동일한 수준의 의미표제 어(lemma) 간에는 의미유사성 정도가 높을수록 선택을 위한 경쟁 이 치열해지기 때문에 점화자극은 표적자극의 어휘화를 방해한다 (예, 배-사과). 이론적으로는 명확해 보이지만 실제로는 두 어휘가 개념을 공유하는 관계인지 아니면 의미유사성이 있는 경쟁적 의미 표제어의 관계인지 모호할 때가 있다. 이러한 모호함은 점화자극의 제시 형태에 의해 어느 정도 해결이 가능하다. 이를테면 점화자극 을 그림으로 제시할 경우 그림의 시각적 이미지의 활성화가 제일 먼 저 개념화부를 자극하기 때문에 표적자극에 대한 의미 촉진효과 로 이어질 가능성이 커진다. 단, 이때 점화자극과 표적자극 간 시간 간격은 매우 짧아야 한다. 그 이유는 시각적 분석, 의미활성화, 의미 처리, 어휘선택, 음운부호화, 조음실행으로 이어지는 순차적인 구 어산출과정의 연속선 상에서, 점화자극에 대한 의미처리만 완료되 고 어휘선택은 본격적으로 일어나기 전 표적자극으로 주의가 옮겨 가야 하기 때문이다. 이는 앞에서 언급하였던 오류 감지 후 일어나 는 빠른 수정과 같이 매우 짧은 순간일 것이다.

이상과 같은 선행연구들에 근거하여 본 연구에서는 개념을 공유 하는 점화자극을 그림으로 제시하고 그것이 표적자극에 미치는 영 향에 대해 알아보고자 하였다. 이때 점화자극과 표적자극 간 간격 은 $600 \mathrm{~ms}$ 으로 하였다. 정상 성인 대상의 선행연구에서 그림 점화 자극의 의미정보만 잔존하여 표적자극에 대해 의미적 정적 점화효 과를 발현하는 stimulus onset asynchrony (SOA)를 $400 \mathrm{~ms}$ 시점이 라고 제안한 바 있다(La Heij, Dirkx, and Kramer, 1990). 이에 근거 하여 정상 아동을 대상으로 예비실험을 진행한 결과, 아동은 성인
보다 어휘인출 처리과정이 유의하게 느린 것이 확인되어 SOA 400 $\mathrm{ms}$ 조건에서는 온전한 의미점화효과를 확인할 수 없었다. 이에 100 $\mathrm{ms}$ 씩 시간 간격을 늘려 예비실험을 진행한 결과 온전한 의미점화 효과가 도출될 수 있는 가장 짧은 SOA는 $600 \mathrm{~ms}$ 이었으며, 본 연구 의 대상은 SSD 아동 또한 포함되었기 때문에 정상 아동을 대상으 로 도출해낸 $600 \mathrm{~ms}$ 의 시간은 결코 긴 시간이 아닐 것이다. 이와 같 은 점화 조건에서 점화자극의 의미점화는 표적자극의 개념화부를 촉진할 수 있을 것으로 기대된다.

점화연구를 $\mathrm{SSD}$ 아동에게 적용한 연구는 국내에서도 찾아볼 수 있다. 그러나 대부분이 점화자극과 표적자극 간 음운적 유사성 에 초점을 두어 하위어휘단계에서 일어나는 형태점화 효과(form priming)에 대해 알아보았다. 이와 달리 본 연구에서는 의미점화 원리에 기반한 어휘전환과제(lexical switching task)를 고안하여 $\mathrm{SSD}$ 아동을 대상으로 점화자극과 표적자극 간 의미점화효과에 대 해 알아보고자 하였다. 어휘전환과제란 두 개의 어휘(점화자극-표 적자극)를 매우 빠른 시간 $(\mathrm{SOA} 600 \mathrm{~ms})$ 에 연속적으로 산출하는 과제로, 이때 두 어휘는 다수의 의미를 공유하거나 또는 전혀 공유 하지 않는다. 대상자는 동반 장애 없이 말소리에만 결함이 있는 순 수 말소리장애(pure speech sound disorder, pure SSD) 아동과 언어 문제를 동반한 말소리장애(speech sound disorder with language disorder, SSD+LD) 아동 그리고 일반 아동(typically developing children, TD)이다. pure SSD 아동은 운동단계인 조음부에만 결함 을 보이는 반면, SSD+LD 아동은 어휘단계, 하위어휘단계, 운동단 계 모두에 결함이 있다고 할 수 있다. 언어장애 동반 여부에 따라 $\mathrm{SSD}$ 를 두 하위집단으로 분류함으로써, 촉진이 일어나는 개념화부 와 결함을 보이는 단계 간 거리에 따라 대상자들의 반응 양상이 다 른지를 비교할 수 있을 것이다. 본 연구에서는 이와 같은 세 집단에 대해 의미관련 여부에 따른 어휘전환과제의 반응시간과 반응정확 도를 비교하였고, SSD 아동이 표적자극에 대해 보인 오반응을 오 류유형 별로 분류하여 pure SSD와 SSD+LD 집단 간 오류유형별 발생비율을 비교하였다. 구어처리과정이 양방향으로 상호작용한 다면 의미점화의 촉진이 개념화부에 제공될 때, 집단 간 기저 어려 움 상의 차이에 따라 의미점화효과가 다르게 나타날 것으로 예측 하였다. 다시 말해 촉진이 제공되는 발원지와 인접한 단계, 즉 어휘 단계부터 결함이 있는 SSD+LD 집단의 점화효과는 인접하지 않은 단계에 결함이 있는 pure SSD 집단에 비해 더 큰 감쇠를 보일 것이 다. 뿐만 아니라 양방향의 상호작용이 비인접 단계에서도 유효하다 면 조음부에만 결함이 있는 pure SSD 집단 역시 온전한 의미점화 효과를 받지 못할 것으로 예측하였다. 수행력뿐 아니라 오류에 대 한 분석은 의미처리와 조음처리의 상호작용 그리고 $\mathrm{SSD}$ 아동이 이 
과정에서 보이는 기저의 어려움에 대해 의미 있는 정보를 제공할 것이다. 이상과 같은 본 연구의 연구질문은 정리하면 다음과 같다. 첫째, $\mathrm{TD}$, pure $\mathrm{SSD}, \mathrm{SSD}+\mathrm{LD}$ 집단 간 의미관련 여부에 따른 어휘 전환과제 반응시간에 차이가 있는가? 둘째, $\mathrm{TD}$, pure $\mathrm{SSD}$, $\mathrm{SSD}+\mathrm{LD}$ 집단 간 의미관련 여부에 따른 어휘전환과제 반응정확도 에 차이가 있는가? 셋째, pure SSD와 SSD+LD 집단 간 어휘전환과 제 수행 시 나타난 오류유형별 오류율에 차이가 있는가?

\section{연구방법}

\section{연구대상}

본 연구의 대상은 4-5세의 SSD 아동 25 명과 TD 아동 15 명이었 다. SSD 아동은 언어발달지체 여부에 따라 pure SSD 아동 15명과 언어발달지체를 동반한 SSD+LD 아동 10 명으로 구분하였다. 먼저 $\mathrm{SSD}$ 아동을 선정하기 위한 공통 기준은 다음과 같다. (1) 우리말 조 음·음운 평가(U-TAP; Kim \& Shin, 2004) 결과 단어 수준의 자음 정확도가 표준편차 $-2 \mathrm{SD}$ 이하에 속하는 아동, (2) 한국판 레이븐 지능검사(K-CPM; Lim, 2004) 결과 비구어성지능의 표준점수가 85점 이상에 속하는 아동, (3) 부모의 보고에 의해 말 산출 및 청각 기관의 구조와 감각상의 결함이 없고, 유전적인 장애가 없는 아동 이다. SSD 아동을 언어발달지체 여부에 따라 세부적으로 분류하 기 위해 다음의 두 가지 기준을 사용하였다. (1) 수용-표현 어휘력 검사(REVT; Kim, Hong, Kim, Jang, \& Lee, 2009) 결과 수용 및 표 현 어휘력이 표준편차 -1 SD 이상인 경우 pure $\mathrm{SSD},-2 \mathrm{SD}$ 이하인 경우 $\mathrm{SSD}+\mathrm{LD}$ 로 분류하였으며, (2) 취학 전 아동의 수용 언어 및 표 현 언어 척도(PRES; Kim, Sung, \& Lee, 2003) 결과 통합언어발달연 령이 생활연령에서 1년 이내에 있는 경우 pure SSD, 1 년 이상 지체 되는 경우 $\mathrm{SSD}+\mathrm{LD}$ 로 구분하였다. TD 아동의 선정 기준은 (1) U$\mathrm{TAP}$ 결과 단어 수준의 자음정확도가 표준편차 $-1 \mathrm{SD}$ 이상에 속하
는 아동, (2) K-CPM 결과 비구어성지능의 표준점수가 85점 이상에 속하는 아동, (3) 부모의 보고에 의해 말 산출 및 청각기관의 구조 와감각상의 결함이 없고, 유전적인 장애가 없는 아동, (4) REVT 결 과 수용 및 표현 어휘력이 -1 SD 이상인 아동, (5) PRES 결과 통합언 어발달연령이 생활연령에서 1년 이내에 있는 아동이다.

세 집단 간 동질성 검정을 위해 일원분산분석을 실시한 결과, 집 단 간 유의미한 차이를 보인 항목은 REVT의 수용 어휘력 $\left(F_{(2,37)}=\right.$ $23.344, p<.001)$ 및 표현 어휘력 $\left(F_{(2,37)}=8.773, p<.01\right), \operatorname{PRES}\left(F_{(2,37)}=\right.$ $13.286, p<.001)$, U-TAP $\left(F_{(2,37)}=116.801, p<.001\right)$ 이었다. Scheffé 사후검정 결과 REVT의 수용 및 표현 어휘력 모두 $\mathrm{SSD}+\mathrm{LD}$ 집단이 pure SSD 집단과 TD 집단보다 유의수준 .05에서 낮은 수행력을 보 였으며, pure SSD 집단과 TD 집단 간 유의미한 차이는 나타나지 않 았다. PRES 결과도 이와 동일하였다. U-TAP의 경우, 유의수준 .05 에서 TD, pure SSD, SSD+LD 순으로 유의하게 높은 수행력을 나타 내었다. 세 집단 간 비구어성지능과 월령에는 유의미한 차이가 없었 으며, 각 집단의 세부적인 특징은 Table 1과 같다.

\section{연구도구}

본 연구에 사용된 어휘전환과제(lexical switching task)는 Hartsuiker 등(2005)이 개발한 그림 변화 패러다임(the picture change paradigm)을 기반으로 제작되었다. 어휘전환과제는 총 60 개의 항 목으로, 점화자극에서 표적자극으로 전환되는 30 개의 전환항목과 점화자극 없이 단순히 표적자극만 제시되는 30 개의 비전환항목으 로 구성되었다. 비전환항목은 전환항목의 사이사이에 배치되었는 데, 이는 과제가 반복됨에 따라 실험대상자가 점화자극과 표적자 극 간 관계를 학습하게 될 가능성, 전략적으로 점화자극에 주의를 기울이지 않고 표적자극만 말할 가능성, 연구자의 의도를 유추하 게 될 가능성 등을 차단하는 통제장치의 역할을 하게 된다.

전환항목은 자극 간 의미관련 여부에 따라 의미관련 조건과 의

Table 1. Participants' characteristics

\begin{tabular}{lcccc}
\hline Characteristic & Pure SSD (N=15) & SSD+LD (N=10) & TD (N=15) & $F$ \\
\hline Age $(\mathrm{mo})$ & $57.27(7.10)$ & $57.70(5.62)$ & $57.20(6.38)$ & 0.02 \\
Nonverbal IO $^{\mathrm{a}}$ & $114.93(8.04)$ & $109.70(9.46)$ & $113.47(10.39)$ & 0.965 \\
Receptive vocabulary score $^{\mathrm{b}}$ & $55.40(9.43)$ & $33.40(12.03)$ & $60.07(8.24)$ & $23.344^{* * *}$ \\
Expressive vocabulary score $^{\mathrm{b}}$ & $53.20(7.79)$ & $35.80(13.98)$ & $58.20(17.01)$ & $8.773^{* *}$ \\
${\text { Combined language age }(\mathrm{mo})^{c}}^{c}$ & $54.33(6.56)$ & $44.10(5.71)$ & $56.53(5.95)$ & $13.286^{* * *}$ \\
PCC $(\%)^{d}$ & $75.62(6.80)$ & $68.12(6.30)$ & $98.60(1.93)$ & $116.801^{* * *}$ \\
\hline
\end{tabular}

Values are presented as mean (SD).

Pure SSD = pure speech sound disorder; $S S D+L D=$ speech sound disorder with language disorder; $T D=$ typically developing.

${ }^{a}$ Korean raven's coloured progressive matrix (Lim, 2004), 'Receptive \& expressive vocabulary test (Kim, Hong, Kim, Jang, \& Lee, 2009); 'Preschool receptive-expressive language scale (Kim, Seong, \& Lee, 2003); dUrimal test of articulation and phonology (Kim \& Shin, 2004).

${ }^{* *} p<.01,{ }^{* * *} p<.001$. 
미비관련 조건으로 구분되었는데, 이를 위해 전환항목에서 사용되 는 점화자극과 표적자극은 의미적으로 관련이 있거나 또는 없어야 하고, 음운적으로는 유사하지 않아야 한다. 의미유사성의 기준은 의미적으로 유사한 어휘를 범주별로 분류한 선행연구(Shin, 2003) 를 토대로 9개의 범주(과일, 채소, 가공식품, 가구, 사물, 교통수단, 자연물, 네발짐승, 신체부위)에 따라 점화자극과 표적자극의 의미 범주가 동일한 의미관련 과제쌍을 제작하였으며, 의미관련 조건에 서 선정된 점화자극을 재배치하여 표적자극과 의미범주가 동일하 지 않은 의미비관련 과제쌍을 제작하였다. 이렇게 선정된 과제 목 록은 의미유사성으로 인한 점화효과를 명확하게 하기 위해 Dell, Schwartz, Martin, Saffran 그리고 Gagnon (1997)의 형태오류 정의 를 기준으로 음운유사성의 영향을 최소화하는 과정을 거쳤다. 또 한 점화자극과 목표자극의 음절 수는 동일해야 하며, 모든 어휘는 그림으로 제시되었다. 비전환항목에서 사용되는 어휘는 모두 15 개 로, 전환항목과 중복되지 않는 의미범주(의복, 곤충, 악기, 학용품, 주방용품)의 단어들로 구성하였다. 이를 통해 전환항목 내에서 점 화자극과 표적자극 간 발생하는 의미점화가 비전환항목의 영향을 받지 않도록 하였다. 비전환항목의 모든 어휘 또한 그림으로 제시 되며, 15 개의 그림 중 5 개는 1 회씩, 5 개는 2 회씩, 5 개는 3 회씩 제시되 어 총 30 개의 비전환항목을 구성하였다. 위의 기준을 충족하여 선 정된 전환 및 비전환항목의 어휘 목록은 Appendix 1에 제시하였다.

주의집중을 위한 응시점(+)이 $1,000 \mathrm{~ms}$ 동안 제시되었다. 응시점 이 사라지고 $500 \mathrm{~ms}$ 이후에 점화자극이 $600 \mathrm{~ms}$ 동안 유지되고, 점 화자극은 표적자극으로 전환되어 $1,000 \mathrm{~ms}$ 동안 제시되었다(Figure 1). 전환항목 사이에는 최소 1 개에서 최대 3 개까지의 비전환항 목을 삽입하여 아동으로 하여금 그림이 언제 바뀔지 예상할 수 없 도록 하였다. 즉, 아동은 전환항목이 제시되는 시점을 예측할 수 없 었는데, 이로 인해 의도가 개입되지 않은 무의식적이고 자동적인 활성화 확산을 확인할 수 있을 것으로 기대하였다. 비전환항목은 연속적으로 같은 그림이 제시되지 않도록 Excel 랜덤함수를 사용 하였으며, 전환항목은 무작위 순서로 제시되었다. 본 과제는 DmDx Display software (Forster \& Forster, 2002)로 제작되었다.

\section{연구절차}

본 실험에 앞서, 실험 절차상의 문제를 점검하기 위해 언어치료학 과 학부생 및 대학원생 30 명과 학령전기 아동 2 명에게 예비 실험을 실시하였다. 연습문항을 포함한 어휘전환과제는 약 20 분 정도 소 요되었으며, 모든 예비 실험은 5 일에 걸쳐 진행되었다. 예비 실험을 통해 실험 절차상의 문제가 없는 것을 확인한 뒤, 본 실험이 이루어 졌다.

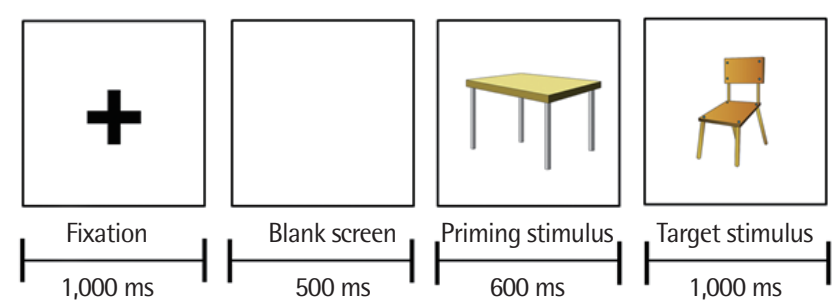

Figure 1. An example of switching item in a lexical switching task.

아동은 먼저 어휘전환과제에 사용된 45 개의 그림 이름을 숙지해 야 했다. 아동이 알지 못하거나 어려워하는 그림이 있을 경우를 대 비하여 모든 그림의 이름을 들려주며 따라 말하도록 지시하였다. 그 후 아동은 그림을 보고 모든 그림의 이름을 스스로 명명하였다. 아동이 모든 그림의 이름을 숙지한 것이 확인되면 5 개의 연습문항 을 실시하였다. 어휘전환과제는 21인치 노트북(15ZD980-MX36K) 으로 실시하였고 아동은 화면과 $40 \mathrm{~cm}$ 정도 거리를 유지하였다. 아 동은 화면에 일정한 간격으로 제시되는 그림의 이름을 명명하였으 며, 제시된 그림(점화자극)은 아동이 예상하지 못한 순간 의미적으 로 관련이 있는/없는 다른 그림(표적자극)으로 바뀌었다. 이때 아 동은 즉각 바뀐 그림의 이름을 명명해야 했다. 연습문항을 통해 과 제의 실시방법을 충분히 이해했다고 판단되면 본 실험을 진행하였 으며, 모든 실험 과정은 $\mathrm{DmDx}$ Display software를 통해 자동으로 녹음되었다.

\section{자료처리}

반응시간 측정

각 아동의 반응시간은 DmDX Display software의 오디오 분석 프로그램인 Check Vocal을 통해 밀리세컨드 단위로 자동 측정되 었다. 반응시간 구간은 그림 자극이 제시된 시점부터 아동의 발화 가 시작되는 시점까지로 지정하였다. 이후 반응시간을 역효율지수 (Inverse Efficiency Score, IES)로 변환하였다(Townsend \& Ashby, 1983). IES는 대상자의 반응 중 오반응의 비율이 $15 \%$ 이상일 경우, 기존의 반응시간 분석방법을 그대로 사용하는 것은 타당하지 않 다(Bruyer \& Brysbeart, 2011)는 연구결과에 기인한 것이다. 예를 들어 모든 문항을 빨리 말하는 것에 집중하는 아동의 경우 오반응 이 증가할 수 있지만, 또 한편으론 정반응 항목의 반응시간은 빨라 질 수 있다. 이때 측정된 빠른 반응시간이 수행력이 좋다는 의미로 해석될 오류를 배제하기 위해 그 대안적 방법으로 IES가 제안되었 으며, 실험대상자가 장애인, 노인, 아동의 경우 이에 대한 효용성이 이미 입증된 바 있다(Bae, Ha, Koo, Hwang, \& Pyun, 2016). 따라서 본 연구에서도 대상자의 정반응과 오반응 모두에 대해 반응시간을 
IES 값으로 변환하여 분석을 실시하였다. IES는 RT (response time)/PC (1-PE)의 값이며, 여기서 $\mathrm{PE}$ 는 오반응의 비율을 말한다. 예를 들어 모두 정반응을 했을 때에는 RT를 '1-0'으로 나누기 때문 에 RT와 IES가 동일한 값을 갖게 되지만, 오반응의 비율이 $50 \%$ 이 상일 경우 RT를 ‘1-0.5’로 나누기 때문에 IES는 RT보다 그 수치가 배로 증가하게 된다.

\section{반응정확도 측정}

반응정확도는 전환항목의 의미관련 조건과 의미비관련 조건에 대해 각각 측정하였다. 점화자극에서 표적자극으로 전환될 때 아 동이 표적자극의 이름을 주어진 시간 안에 정확하게 말할 경우 1 점 을 획득하였다. 이때 점화자극에 대한 오류는 반응정확도 측정에 포함되지 않았다. 예를 들어 점화자극이 /기린/, 표적자극이 /사자/ 인 경우, 표적자극을 정반응 하였다면 점화자극 /기린/은 생략하거 나 오류를 보여도 1 점을 획득하였다. 의미관련 조건과 의미비관련 조건에서 획득할 수 있는 최대 점수는 각각 15 점이었다. 반응정확 도는 조건별 전체 문항 수(15문항)에 대한 획득한 점수의 비율을 구한 뒤, 100을 곱하여 백분율(\%)로 산출하였다.

\section{오류유형별 오류율 측정}

어휘전환과제 수행 시 분포된 오류유형을 분석하고 그에 대한 오 류율을 측정하였다. 오류유형은 한 아동에게 적어도 3회 이상 의미 있는 오류가 출현했을 때 분석을 실시했으므로, $\mathrm{TD}$ 집단 전체와 소수의 오류를 보인 pure SSD 아동 5명은 분석에서 제외되었다. 따 라서 오류유형 분석의 대상은 pure SSD 집단과 SSD+LD 집단 각각 10 명씩이었다. 주어진 시간 내에 목표 어휘를 정확히 말하지 못한 경우를 의미 있는 오류라고 간주하였으며, 이때 무반응 및 시간초 과와 같이 발화가 산출되지 않았거나 산출되었어도 시간이 지연되 어 녹음되지 않은 오류에 대한 분석은 이루어지지 않았다.

오류유형은 Dell 등(1997)의 연구에 근거하여 의미오류(semantic error), 형태오류(formal error), 혼합오류(mixed error), 비관련 오류(unrelated error), 비단어오류(nonword error)로 분류하였고, 여기에 대상자들이 보인 새로운 오류 유형인 반복오류(repeated error)를 추가하였다. 단, 본 연구의 경우 표적자극보다 점화자극과 관련 있는 오류들이 많이 관찰되어, 점화자극을 기준으로 오류유 형을 다음과 같이 정의하였다. 의미오류는 점화자극과 의미적으로 유사한 다른 단어를 산출한 오류이다(양-말). 의미관련 조건에서는 점화자극과 표적자극이 의미를 공유하기 때문에, 결과적으로 이때 의 의미오류는 표적자극과도 의미적으로 유사하다. 형태오류는 점 화자극과 음운적으로 유사한 단어를 산출한 오류(발-달), 혼합오
류는 점화자극과 의미와 음운 모두에서 유사한 단어를 산출한 경 우(발-발가락), 비관련오류는 점화자극과 의미와 음운 모두에서 유사하지 않은 단어를 산출한 오류(소-칼), 비단어오류는 우리말 에 존재하지 않는 말소리조합을 산출한 오류(기린-기처)로 정의하 였으며, 반복오류는 점화자극을 그대로 한 번 더 반복한 오류를 말 한다. 오류유형에 대한 오류율은 대상자의 전체 오류 수에 대한 각 오류유형 수의 비율을 구한 뒤 100을 곱하여 백분율(\%)로 산출하 였다.

\section{통계분석}

자료의 통계처리는 SPSS version 23.0 (IBM, Armonk, NY, USA) 을 사용하여 분석하였다. 첫째, 어휘전환과제에서 세 집단 간 의미 관련 조건에 따른 반응시간의 차이를 알아보기 위해 1피험자 간-1 피험자 내 혼합설계에 의한 반복측정 분산분석(Repeated Measure ANOVA)을 실시하였다. 둘째, 어휘전환과제에서 세 집단 간 의미 관련 조건에 따른 반응정확도의 차이를 알아보기 위해 1 피험자 간-1피험자 내 혼합설계에 의한 반복측정 분산분석을 실시하였다. 셋째, 의미관련 조건에서 두 집단 간 오류유형에 따른 오류율의 차 이를 알아보기 위해 1피험자 간-1피험자 내 혼합설계에 의한 반복 측정 분산분석을 실시하였다. 피험자 간 사후검정은 Scheffé 사후 검정을 사용하였으며, 피험자 내 주효과 검정은 다중비교에 따른 1 종 오류의 증가를 통제하기 위해 Bonferroni 사후검정을 사용하였 다. 피험자 간, 피험자 내 상호작용효과 검정을 위해 COMPARE 하 위명령 Syntax를 입력하여 사후검정을 실시하였다.

\section{연구결과}

\section{세 집단 간 의미관련 여부에 따른 반응시간 비교}

세 집단 간 의미관련 여부에 따른 반응시간에 대한 기술통계는 Table 2와 같다. 세 집단 모두 의미비관련 조건보다 의미관련 조건 에서 어휘전환과제의 반응시간이 빨랐으며, 의미관련 여부에 상관 없이 $\mathrm{TD}$ 집단, pure $\mathrm{SSD}$ 집단, $\mathrm{SSD}+\mathrm{LD}$ 집단 순으로 반응시간이 빨랐다. 이러한 차이가 통계적으로 유의한지 확인하기 위해 혼합 설계에 따른 반복측정 분산분석을 실시한 결과, 세 집단 간 차이 $\left(F_{(2,37)}=88.315, p<.001\right)$ 가 유의하였다. 집단 내 의미관련 여부에 따른 주효과 $\left(F_{(1,37)}=70.442, p<.001\right)$ 가 유의하여, 의미관련 조건에 서의 반응시간이 의미비관련 조건에 비해 빠른 것을 알 수 있었다. 의미관련 여부와 집단 간 상호작용효과 $\left(F_{(2,37)}=5.139, p<.05\right)$ 또한 유의하였다.

집단 간 차이에 대한 사후검정 결과 $\mathrm{TD}$ 집단은 pure SSD 집단 
Table 2. Descriptive statistics for response time (ms) in three groups

\begin{tabular}{lrc}
\hline Group & \multicolumn{1}{c}{ Semantic } & Non-semantic \\
\hline TD $(N=15)$ & $979.61(103.37)$ & $1,549.79(179.01)$ \\
Pure SSD $(\mathrm{N}=15)$ & $1,160.12(103.37)$ & $2,670.64(179.01)$ \\
SSD+LD $(\mathrm{N}=10)$ & $2,562.67(126.60)$ & $3,956.56(219.25)$ \\
\hline
\end{tabular}

Values are presented as mean (SD).

$\mathrm{TD}$ = typically developing; Pure SSD = pure speech sound disorder; SSD+LD = speech sound disorder with language disorder.

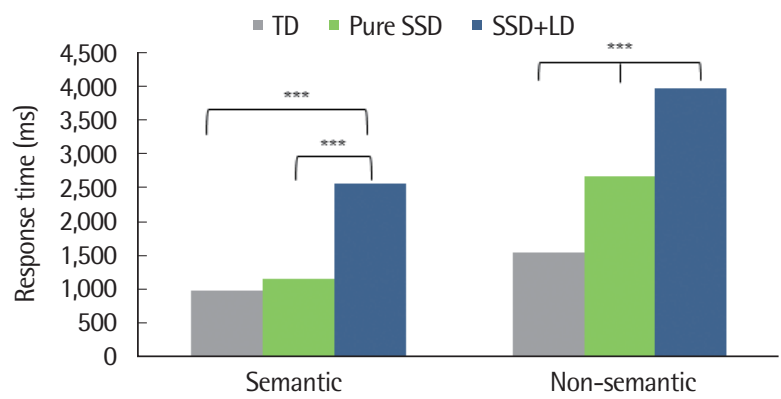

Figure 2. Response time of three groups on semantic and non-semantic conditions. TD=typically developing; Pure SSD=pure speech sound disorder; $\mathrm{SSD}+\mathrm{LD}=$ speech sound disorder with language disorder. ${ }^{* * *} p<.001$.

$(p<.001)$ 과 $\mathrm{SSD}+\mathrm{LD}$ 집단 $(p<.001)$ 보다 유의하게 반응시간이 빨 랐으며, pure SSD 집단은 $\mathrm{SSD}+\mathrm{LD}$ 집단 $(p<.001)$ 보다 반응시간이 유의하게 빨랐다. 집단과 의미관련 여부 간 상호작용효과에 대한 사후검정 결과, $\mathrm{TD}$ 집단은 의미관련 조건과 의미비관련 조건 간 유 의한 차이를 보이지 않았으나( $p>.05)$, pure SSD 집단과 SSD+LD 집단은 의미적으로 관련 있는 점화자극이 제시될 때 유의하게 빠 른 반응시간을 보였다 $(p<.001)$. 또한 의미비관련 조건에서의 반응 시간은 $\mathrm{TD}$ 집단, pure $\mathrm{SSD}$ 집단, $\mathrm{SSD}+\mathrm{LD}$ 집단 순으로 유의하게 빨랐으나 $(p<.001)$, 의미관련 조건에서는 TD와 pure SSD 간 반응 시간에 유의한 차이를 보이지 않았다( $p>.05)$. 즉, 의미적으로 유사 한 점화자극이 제시되었을 때 pure SSD 집단은 TD 집단만큼 빠른 반응시간을 보였다(Figure 2).

\section{세 집단 간 의미관련 여부에 따른 반응정확도 비교}

세 집단 간 의미관련 여부에 따른 반응정확도에 대한 기술통계 는 Table 3 과 같다. 세 집단 모두 의미비관련 조건보다 의미관련 조 건에서 어휘전환과제의 반응정확도가 높았으며, 의미관련 여부에 상관없이 TD 집단, pure SSD 집단, $\mathrm{SSD}+\mathrm{LD}$ 집단 순으로 반응정확 도가 높았다. 이러한 차이가 통계적으로 유의한지 확인하기 위해 혼합설계에 따른 반복측정 분산분석을 실시한 결과, 세 집단 간 차 이 $\left(F_{(2,37)}=67.314, p<.001\right)$ 가 유의하였다. 집단 내 의미관련 여부에 따른 주효과 $\left(F_{(2,37)}=39.123, p<.001\right)$ 가 유의하여, 의미관련 조건에
Table 3. Descriptive statistics for response accuracy (\%) in three groups

\begin{tabular}{lcc}
\hline Group & Semantic & Non-semantic \\
\hline TD $(\mathrm{N}=15)$ & $92.92(2.40)$ & $79.15(2.61)$ \\
Pure SSD $(\mathrm{N}=15)$ & $84.45(2.40)$ & $64.91(2.61)$ \\
SSD+LD $(\mathrm{N}=10)$ & $52.02(2.94)$ & $48.71(3.19)$ \\
\hline
\end{tabular}

Values are presented as mean (SD).

$\mathrm{TD}$ =typically developing; Pure SSD = pure speech sound disorder; SSD+LD = speech sound disorder with language disorder.

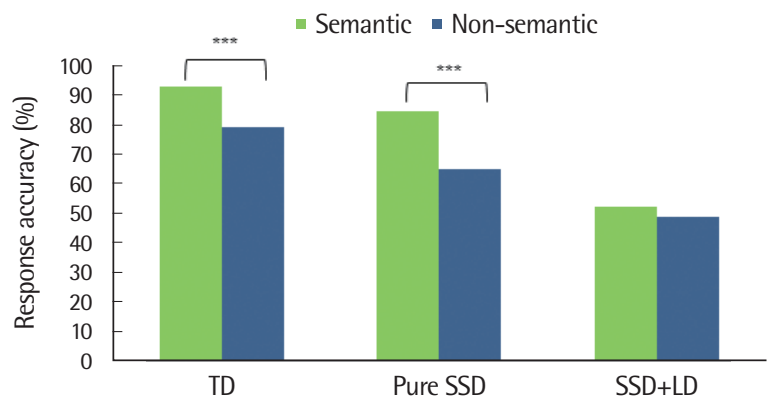

Figure 3. Response accuracy of semantic and non-semantic conditions in three groups. TD= typically developing; Pure SSD = pure speech sound disorder; SSD+ $\mathrm{LD}=$ speech sound disorder with language disorder. ${ }^{* * *} p<.001$.

서의 반응정확도가 의미비관련 조건에 비해 유의하게 높은 것을 알 수 있었다. 의미관련 여부와 집단 간 상호작용효과 $(F(2,37)=5.395$, $p<.01)$ 또한 유의하였다.

집단 간 차이에 대한 사후검정 결과 $\mathrm{TD}$ 집단은 pure SSD 집단 $(p<.01)$ 과 $\mathrm{SSD}+\mathrm{LD}$ 집단 $(p<.001)$ 보다 유의하게 반응정확도가 높 았으며, pure SSD 집단은 SSD+LD 집단 $(p<.001)$ 보다 반응정확도 가 유의하게 높았다. 의미관련 여부와 집단 간 상호작용 효과에 대 한 사후검정 결과, $\mathrm{TD}$ 집단과 pure SSD 집단은 의미적으로 관련 있는 점화자극이 제시되었을 때 유의하게 높은 반응정확도를 보였 으나 $(p<.001), \mathrm{SSD}+\mathrm{LD}$ 집단의 경우 의미관련 조건과 의미비관련 조건 간 반응정확도에 유의한 차이를 보이지 않았다 $(p>.05$ )(Figure 3). 또한 TD 집단, pure SSD 집단, SSD+LD 집단 순으로 반응정 확도가 유의하게 높았는데 $(p<.01)$, 이러한 경향은 의미관련 조건 과 의미비관련 조건 모두에서 동일하게 나타났다.

\section{집단 간 의미관련 조건에서의 오류유형별 오류율 비교}

두 집단 간 의미관련 조건에서 보인 오류유형별 오류율에 대한 기술통계는 Table 4 와 같다. pure SSD 집단의 평균 오류율은 의미 오류 $40.31 \%$ (22.77), 형태오류 $4.56 \%$ (7.81), 혼합오류 9.50\% (13.20), 비관련오류 $34.02 \%$ (10.69), 반복오류 6.82\% (9.49), 비단어오류 $4.32 \%$ (7.18)로, 의미오류율이 가장 높았다. SSD+LD 집단의 평균 오류율은 의미오류 $26.81 \%$ (19.65), 형태오류 $34.81 \%$ (21.10), 혼합 
Table 4. Descriptive statistics for percentage of error types (\%) in two groups

\begin{tabular}{lcccccc}
\hline & Semantic & Formal & Mixed & Unrelated & Repeated & Nonword \\
\hline Pure SSD $(\mathrm{N}=10)$ & $40.31(22.77)$ & $4.56(7.81)$ & $9.50(13.20)$ & $34.02(10.69)$ & $6.82(9.49)$ & $4.32(7.18)$ \\
SSD+LD $(\mathrm{N}=10)$ & $26.81(19.65)$ & $34.81(21.10)$ & $9.99(17.91)$ & $17.99(20.68)$ & $10.33(18.08)$ & $.00(.00)$ \\
\hline
\end{tabular}

Values are presented as mean (SD).

Pure SSD = pure speech sound disorder; $S S D+L D=$ speech sound disorder with language disorder.

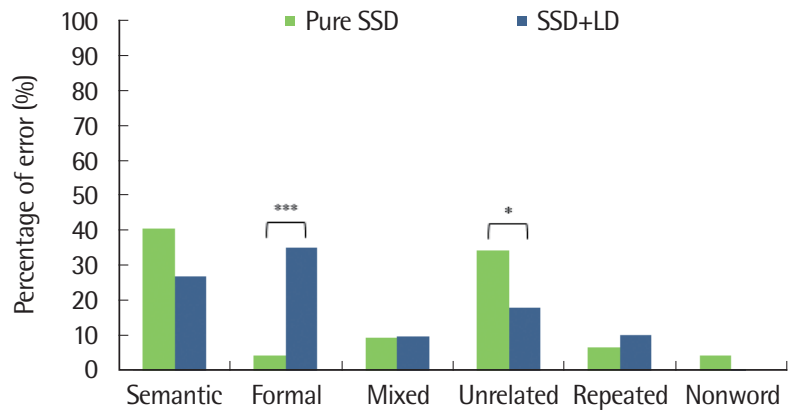

Figure 4. Percentage of error types in two groups. Pure SSD=pure speech sound disorder; SSD+LD= speech sound disorder with language disorder. ${ }^{*} p<.05,{ }^{* * *} p<.001$.

오류 9.99\% (17.91), 비관련오류 17.99\% (20.68), 반복오류 $10.33 \%$ (18.08), 비단어오류 .00\% (.00)로 형태오류율이 가장 높았다. 이에 대한 통계적 유의성을 검정하기 위해 혼합설계에 따른 반복측정 분산분석을 실시한 결과, 두 집단 간 차이 $\left(F_{(1,18)}=.008, p>.05\right)$ 가 유 의하지 않았다. 이는 전체 오류에 대한 각 오류유형별 비율을 백분 율로 비교하였기 때문에 나타난 당연한 결과이다. 반면 집단 내 오 류유형별 오류율에 따른 주효과 $\left(F_{(5,90)}=9.788, p<.001\right)$ 는 유의하 였고, 오류유형과 집단 간 상호작용효과 $\left(F_{(5,90)}=4.805, p<.01\right)$ 또 한 유의하였다.

오류유형의 주효과에 대한 사후검정 결과, 의미오류는 혼합오 류, 반복오류 및 비단어오류보다 오류율이 유의하게 높았다 $(p<.05)$. 형태오류는 비단어오류보다, 반복오류는 비관련오류보 다, 비관련오류는 비단어오류보다 유의하게 높은 오류율을 보였다 $(p<.05)$. 오류유형과 집단 간 상호작용효과에 대한 사후검정 결과, 형태오류 $(p<.001)$ 와 비관련오류 $(p<.05)$ 에서 두 집단 간 차이가 유의하였다. 비관련오류율은 pure SSD 집단에서 유의하게 높았던 반면, 형태오류율은 SSD+LD에서 유의하게 높았다(Figure 4).

\section{논의 및 결론}

본 연구에서는 구어산출과정에 있어 pure SSD 집단과 SSD+LD 집단 간 기저 어려움 상의 차이점에 주목하여, 두 집단에서 의미점 화효과가 다르게 나타날 것이라는 기대 하에 어휘전환과제를 실시
하였다. 어휘전환과제 수행에 의미점화가 미치는 영향을 반응시간 과 반응정확도로 측정하였고, $\mathrm{SSD}$ 하위집단 간 오류유형에 따른 오류율의 차이를 분석하였다. 궁극적으로는 개념화부를 촉진하는 또는 촉진하지 않는 어휘전환과제에 대해 조음부에 결함이 있는 또는 결함이 없는 대상자들의 수행 양상이 어떻게 다른지를 비교 함으로써, 구어처리과정의 비인접 단계인 개념화부와 조음부가 양 방향적으로 상호작용하는지를 알아보기 위한 것이었다. 그 결과 집단에 상관없이 의미비관련보다 의미관련 조건에서 유의하게 반 응시간이 빠르고 반응정확도가 높아, 점화자극에서 공유된 의미 는 표적자극을 촉진한다는 것을 확인하였다. 또한 의미관련 여부 에 상관없이 반응속도와 반응정확도가 $\mathrm{TD}$, pure $\mathrm{SSD}, \mathrm{SSD}+\mathrm{LD}$ 집 단 순으로 유의한 차이를 나타내어, $\mathrm{TD}$ 집단보다 SSD 집단이 과제 수행에 더 어려움을 보이고 SSD 두 하위집단 간에도 어려움 정도 에 차이가 있음을 알 수 있었다. 오류분석을 통해 pure SSD 집단의 경우 의미오류가, $\mathrm{SSD}+\mathrm{LD}$ 집단의 경우 형태오류가 가장 많이 나 타난 오류유형임을 관찰하였다. 그 이외에 유의한 상호작용효과에 대해서는 보다 심도 있는 논의가 필요할 것으로 생각되어, 연구질 문 각각에 대해 개별적인 고찰을 실시하고자 한다.

먼저 반응속도에 대한 고찰이다. 앞에서도 언급하였듯이 집단에 상관없이 의미비관련보다 의미관련 조건에서 더 빠른 반응속도를 보이며 의미점화의 이득을 확인하였다. 그러나 상호작용효과에 대 한 사후검정 결과 이득의 정도에 있어 집단별로 명확한 차이가 관 찰되었다. $\mathrm{TD}$ 집단은 의미비관련보다 의미관련 조건에서 평균적 으로 더 빠른 반응속도를 보였지만 그 차이가 통계적으로는 유의 하지는 않았다. 반면 pure SSD와 SSD+LD 집단에서는 두 조건 간 차이가 통계적으로도 유의하여, 의미비관련보다 의미관련 조건에 서 반응속도가 유의하게 빨라짐을 확인하였다. 즉, 구어산출단계 의 연쇄적 활성화로 인해 각 단계의 시간적 중첩이 발생하는 동안 개념화부의 촉진은 결함이 있는 어휘단계부터 조음부까지 (SSD+LD 집단의 경우), 혹은 조음부에 (pure SSD 집단의 경우) 연 쇄적인 영향을 미쳐, 보다 빠르게 목표어를 탐색하고 산출할 수 있 도록 도움을 주었다. 더 나아가 pure SSD 집단의 경우 의미관련 조 건에서는 $\mathrm{TD}$ 집단과 반응속도에 유의한 차이가 없어졌다. 이는 개 념화부 촉진으로 인해 pure SSD 집단이 얻은 이익은 $\mathrm{SSD}+\mathrm{LD}$ 집단 
보다도 더 컸다는 것을 의미한다. 즉, 의미적으로 유사한 점화자극 이 제시되면 pure SSD 집단은 TD 집단만큼이나 빠른 반응속도를 보인다는 것이다. 이러한 결과로 인해 의미점화의 촉진이 개념화부 에 제공될 때, 그 발원지와 인접하지 않은 단계에만 결함이 있는 pure SSD 집단에게는 그 효과가 강력하게 작용하여 TD 집단과 유 사한 수행력을 보이게 됨을 유추할 수 있다. 다시 말해 의미점화자 극으로 인한 개념화부의 촉진은, 중간 과정인 어휘단계의 결함이 없을 경우, 인접하지 않은 조음부까지 활발한 영향을 미쳐 TD 집 단만큼 빠르게 목표어를 산출할 수 있도록 도움을 줄 수 있다.

반면 반응정확도는 의미관련과 의미비관련 조건 모두에서 $\mathrm{TD}$ 집단, pure SSD 집단, SSD+LD 집단 순으로 유의하게 높았다. 앞에 서 살펴보았듯이 반응속도의 경우 의미관련 조건에서 pure SSD 집 단이 TD 집단만큼 빠른 반응속도를 보여 두 집단 간 유의한 차이 가 없어졌던 반면, 반응정확도는 여전히 차이를 보였다. 이는 반응 정확도보다 반응시간이 pure SSD 집단의 수행력 향상을 더욱 민 감하게 보여주는 지표임을 시사한다. 이러한 결과에 대해 이전 단 계인 개념화부의 촉진은 어휘인출의 속도를 빨라지게 하였으나 이 후 단계인 조음부의 결함으로 인해 촉진의 확산이 방해를 받았고, 이 때문에 정확한 반응으로는 이어지지 못했을 가능성을 생각해 볼 수 있다. 이와 유사한 양상은 SSD+LD 집단에서도 나타났다. 앞 에서 $\mathrm{SSD}+\mathrm{LD}$ 집단의 반응속도는 의미비관련보다 의미관련 조건 에서 유의하게 빨랐음을 확인하였으나, 반응정확도에서는 두 조건 간 유의한 차이를 보이지 않았다. 이는 SSD+LD 집단의 경우 pure $\mathrm{SSD}$ 집단보다도 점화효과의 감쇠가 뚜렷하여, 의미점화효과가 반 응정확도로 전혀 연결되지 않았음을 보여준다. 구어처리과정이 연 쇄적으로 활성화된다는 것을 상기할 때, $\mathrm{SSD}+\mathrm{LD}$ 집단의 기저 결 함이 어휘단계부터이고 그 결함 지점이 촉진을 제공한 개념화부와 더욱 인접하다면 $\mathrm{SSD}+\mathrm{LD}$ 집단에서 더 큰 점화효과의 감쇠를 보인 것은 어쩌면 당연한 결과로 여겨진다.

마지막으로 pure SSD 집단과 SSD+LD 집단이 보인 오류유형별 오류율 비교를 통해, 집단 간 어휘전환과제 반응의 질적 차이를 확 인할 수 있었다. 두 집단이 차이를 보인 오류유형은 형태오류와 비 관련오류였는데, 구체적으로는 pure SSD 집단은 비관련오류를, $\mathrm{SSD}+\mathrm{LD}$ 집단은 형태오류를 유의하게 많이 보였다. 이러한 결과는 각 집단의 상대적으로 느린 처리속도와 비효율적인 주의할당을 반 영하는 것으로 보인다. 본 연구에서 사용된 어휘전환과제의 특징 은 빠른 전환으로, $600 \mathrm{~ms}$ 라는 매우 짧은 시간 안에 점화자극에서 표적자극으로 자극이 바뀐다. 빠르게 전환되기 때문에 표적자극의 처리가 진행되는 동안에도 점화자극에 대한 잔여활성화(residual activation)가 여전히 남아 영향을 미칠 수 있다(Tydgat, Diepen- daele, Hartsuiker, \& Pickering, 2012). 이러한 가설에 근거하여 $\mathrm{SSD}+\mathrm{LD}$ 집단이 보인 형태오류에 대해, 대상자들의 지체된 처리속 도로 인해 점화자극의 음운표상의 잔여활성화가 표적자극의 산출 시점에서도 불필요하게 남아 있었고, 때문에 표적자극을 산출하는 대신 점화자극과음운적으로 유사한 형태오류를 유의하게 많이 보 였을 가능성을 생각해볼 수 있다. 더불어 표적자극이 제시됨과 동 시에 점화자극의 정보를 재빠르게 억제하고 표적자극에 집중해야 함에도 불구하고 여전히 점화자극으로 분산된 주의력, 즉 효율적 주의할당의 실패가 이와 같은 오류를 야기했을 가능성도 생각해 볼수있다.

pure SSD 집단의 비관련오류도 이와 비슷한 맥락에서 설명이 가 능하다. pure SSD 집단이 보인 비관련오류를 검토해본 결과, 의미 비관련 조건에서 표적자극과 의미적으로 관련 있는 단어를 잘못 말한 경우가 전체 비관련오류의 $92 \%$ 이상 해당하였다. 예를 들어 점화자극과 표적자극이 각각 '침대'와 '사자'일 때, '사자'의 영향으 로 표적자극을 /호랑이/라고 산출하였어도 점화자극인 '침대'와는 의미 및 음운적으로 관련이 없기 때문에 비관련오류에 속하게 된 다. 이에 대해서는 표적자극을 조음해야 하는 시점에 여전히 표적 자극의 의미처리가 진행되고 있고 이때 분산된 주의력으로 인해 의 미처리가 방해를 받게 되어, 그 결과 표적자극과 의미적으로 유사 한 다른 단어를 산출했을 가능성을 생각해볼 수 있다. 정리하면 $\mathrm{SSD}+\mathrm{LD}$ 집단은 점화자극의 음운표상에, pure SSD 집단은 표적자 극의 의미표상에 머무른 상태에서 주의에 방해를 받았고, 그로 인 해 두 집단 간 질적으로 다른 오류반응이 야기되었다는 것이다. 이 는 두 집단 모두에서 지체된 처리속도를 반영하지만, 둘 중 $\mathrm{SSD}+\mathrm{LD}$ 집단의 속도가 더 느리다는 해석을 가능하게 해준다.

이상과 같은 결과는 SSD 아동의 의사소통 중재 시 고려해야 할 점에 대해서도 시사하는 바가 있다. 정도에는 차이가 있었지만 pure SSD 집단과 SSD+LD 집단 모두에게 의미적 촉진은 어휘인출 에 긍정적인 영향을 미쳤다. SSD 아동에게 조음음운적인 중재가 필요한 것은 명백한 사실이나, 이때 의미적 촉진을 함께 제공한다 면 그 수행력이 보다 향상될 수 있을 것으로 기대해볼 만하다. 오류 분석을 통해, 마찬가지로 집단 간 정도에 차이는 있었지만 SSD 아 동들의 과제 처리속도가 전반적으로 지연되었음을 확인하였다. 이 것이 일상대화 상황 또는 중재활동 시, $\mathrm{SSD}$ 아동으로 하여금 바람 직한 반응을 유도하기위해 보다 충분한 시간이 제공되어야 하는 이유일 것이다. 또한 연구결과 확인된 비인접 단계의 상호작용효과 는 pure SSD로 진단받았다 하더라도 의사소통활동 시 그 이전 단 계인 언어처리과정에 전혀 문제가 없을 것으로 기대해서는 안 된다 는 것을 시사한다. 언어의 한 영역의 결함은 다른 영역에도 영향을 
줄 수 있기 때문에, 이러한 상호영향에 유의하여 각 영역의 독립적 평가뿐 아니라 모든 영역을 동시에 아우를 수 있는 총체적인 평가 또한 병행되어야 할 것이다. 개념화부의 활성화와 조음부의 결함이 라는 비인접 단계의 상호작용 효과는 SSD 아동의 의사소통능력에 긍정적 및 부정적 측면을 모두 제공하는 것으로 보인다. 강점을 잘 활용하면 약점을 보완할 수 있는 반면, 약점의 부각은 강점에까지 부정적인 영향을 미칠 수 있다는 것을 염두에 두어야 할 것이다.

\section{REFERENCES}

Alario, F. X., Segui, J., \& Ferrand, L. (2000) Semantic and associative priming in picture naming. Journal of Experimental Psychology: Human Experimental Psychology, 53(3), 741-764.

Bae, S. R., Ha, J. W., Koo, M. M., Hwang, Y. M., \& Pyun, S. B. (2016). New phonological representation of children with speech sound disorders. Communication Sciences \& Disorders, 21(1), 24-36.

Bloem, I., Van den Boogaard, S., \& La Heij, W. (2004). Semantic facilitation and semantic interference in language production: further evidence for the conceptual selection model of lexical access. Journal of Memory and Language, 51(2), 307-323.

Bruyer, R., \& Brysbaert, M. (2011). Combining speed and accuracy in cognitive psychology: is the inverse efficiency score (IES) a better dependent variable than the mean reaction time (RT) and the percentage of errors (PE)? Psychologica Belgica, 51(1), 5-13.

Cutting, J. C., \& Ferreira, V. S. (1999). Semantic and phonological information flow in the production lexicon. Journal of Experimental Psychology: Learning, Memory, and Cognition, 25(2), 318-344.

Dell, G. S. (1986). A spreading-activation theory of retrieval in sentence production. Psychological Review, 93(3), 283-321.

Dell, G. S., Chang, F., \& Griffin, Z. M. (1999). Connectionist models of language production: lexical access and grammatical encoding. Cognitive Science, 23(4), 517-542.

Dell, G. S., Schwartz, M. F., Martin, N., Saffran, E. M., \& Gagnon, D. A. (1997). Lexical access in aphasic and nonaphasic speakers. Psychological Review, 104(4), 801-838.

Fink, A., Oppenheim, G. M., \& Goldrick, M. (2017). Interaction between lexical access and articulation. Language, Cognition and Neuroscience, $33(1), 12-24$.

Forster, K., \& Forster, J. (2002). DMDX display software. Tucson, AZ: Univer- sity of Arizona.

Goldrick, M., McClain, R., Cibelli, E., Adi, Y., Gustafson, E., Moers, C., \& Keshet, J. (2019). The influence of lexical selection disruptions on articulation. Journal of Experimental Psychology: Learning, Memory, and Cognition. 45(6), 1107-1141.

Hartsuiker, R. J., Pickering, M. J., \& de Jong, N. H. (2005). Semantic and phonological context effects in speech error repair. Journal of Experimental Psychology: Learning, Memory, and Cognition, 31(5), 921-932.

Heisler, L., Goffman, L., \& Younger, B. (2010). Lexical and articulatory interactions in children's language production. Developmental Science, 13(5), $722-730$

Kim, N. Y., \& Ha, J. W. (2018). Effects of the word frequency and the phonetic complexity on lexical retrieval in children with pure speech sound disorders. Communication Sciences \& Disorders, 23(4), 971-981.

Kim, Y. T., Hong, G. H., Kim, K. H., Jang, H. S., \& Lee, J. Y. (2009). Receptive and Expressive Vocabulary Test (REVT). Seoul: Seoul Community Rehabilitation Center.

Kim, Y. T., \& Shin, M. J. (2004). Urimal Test of Articulation and Phonology (U-TAP). Seoul: Hakjisa.

Kim, Y. T., Sung, T. J., \& Lee, Y. K. (2003). Preschool Receptive-Expressive Language Scale (PRES). Seoul: Seoul Community Rehabilitation Center.

La Heij, W., Dirkx, J., \& Kramer, P. (1990). Categorical interference and associative priming in picture naming. British Journal of Psychology, 81(4), 511-525.

Levelt, W. J. M., Roelofs, A., \& Meyer, A. S. (1999). A theory of lexical access in speech production. Behavioral and Brain Sciences, 22, 1-38.

Lim, H. C. (2004). Korean Raven's Coloured Progressive Matrix (K-CPM). Seoul: Hankuk Guidance.

Peterson, R. R., \& Savoy, P. (1998). Lexical selection and phonological encoding during language production: evidence for cascaded processing. Journal of Experimental Psychology: Learning, Memory, and Cognition, 24(3), 539557.

Shin, H. J. (2003). A validation of the category norms collected through internet. Journal of Experimental Psychology, 15(2), 303-347.

Townsend, J. T., \& Ashby, F. G. (1983). Stochastic modeling of elementary psychological processes. Cambridge: Cambridge University Press.

Tydgat, I., Diependaele, K., Hartsuiker, R. J., \& Pickering, M. J. (2012). How lingering representations of abandoned context words affect speech production. Acta Psychologica, 140(3), 218-229. 
Da-Hee Oh, et al. • Semantic Priming Effects on the Lexical Switching Task

Appendix 1. The item list of the lexical switching task

\begin{tabular}{|c|c|c|c|}
\hline \multicolumn{3}{|c|}{ Switching item } & \multirow{3}{*}{ Non-switching item } \\
\hline \multirow{2}{*}{ Priming stimulus } & \multicolumn{2}{|c|}{ Target stimulus } & \\
\hline & Semantic condition & Non-semantic condition & \\
\hline 발 & 손 & 해 & 신발 \\
\hline 소 & 말 & 입 & 개미 \\
\hline 코 & 입 & 말 & 치마 \\
\hline 달 & 해 & 뱀 & 국자 \\
\hline 양 & 뱀 & 손 & 나비 \\
\hline 책상 & 의자 & 로봇 & 냄비 \\
\hline 그네 & 시소 & 오이 & 기타 \\
\hline 당근 & 오이 & 시소 & 바지 \\
\hline 인형 & 로봇 & 기차 & 연필 \\
\hline 버스 & 기차 & 소파 & 피아노 \\
\hline 메론 & 수박 & 의자 & 숟가락 \\
\hline 침대 & 소파 & 사자 & 달팽이 \\
\hline 기린 & 사자 & 수박 & 지우개 \\
\hline 솜사탕 & 케이크 & 거북이 & 탬버린 \\
\hline 다람쥐 & 거북이 & 케이크 & 크레파스 \\
\hline
\end{tabular}




\section{국문초록}

\section{말소리장애 아동과 일반 아동의 어휘전환과제 수행에 의미점화가 미치는 영향}

오다희 ${ }^{1} \cdot$ 하지완

${ }^{1}$ 대구대학교 일반대학원 재활과학과, ${ }^{2}$ 대구대학교 언어치료학과

배경 및 목적: 본 연구의 목적은 말소리장애 및 언어장애 동반 여부에 따라 달라질 것이라 예상되는 의미점화 효과의 양상을 비교하여 비인접단계의 상호작용효과를 확인하는 것이다. 방법: 4-5세의 순수말소리장애(pure SSD) 아동 15명과 언어장애를 동반한 말소리장 애(pure SSD+LD) 아동 10 명, 일반(TD) 아동 15 명을 대상으로 어휘전환과제를 실시하였다. 어휘전환과제는 빠르게 전환되는 두 개의 그림을 명명하는 과제로, 의미관련 여부에 따라 의미관련 조건과 의미비관련 조건으로 구분되었다. 이때의 수행력은 반응에 대한 속도 와 정확도로 측정하였으며, 오반응에 대한 오류유형을 분석하였다. 결과: 첫째, 반응속도는 의미관련조건에 한해 pure SSD 집단과 TD 집단 간 차이가 유의하지 않았다. 둘째, 반응정확도는 pure SSD 집단과 TD 집단 간 차이가 유의하였으며, SSD+LD 집단의 경우 집단 내 의미관련 여부에 따른 차이가 유의하지 않았다. 셋째, pure SSD 집단과 SSD+LD 집단 간 오류유형을 비교한 결과, pure SSD 집단은 비 관련오류가, SSD+LD 집단은 형태오류가 유의하게 많이 발생하였다. 논의 및 결론: 각 단계의 양방향 간 상호작용이 정적점화 효과의 감쇠를 초래함을 증명하였고, 이는 특정 영역에 결함이 있는 의사소통장애에 관한 연구가 보다 광범위한 영역에서 실현되어야 함을 시 사한다.

핵심어: 말소리장애, 의미점화, 비인접단계의 상호작용 효과

이 연구는 2019학년도 대구대학교 학술연구비지원으로 수행되었음.

\section{참고문헌}

김나연, 하지완(2018). 순수 말소리장애 아동과 일반아동 간 단어빈도 및 조음복잡성에 따른 어휘인출능력 비교. Communication Sciences \& Disorders, 23(4), 971-981.

김영태, 성태제, 이윤경(2003). 취학전 아동의 수용언어 및 표현언어 척도(PRES). 서울: 서울장애인종합복지관.

김영태, 신문자(2004). 우리말 조음·음운평가(U-TAP). 서울: 학지사.

김영태, 홍경훈, 김경희, 장혜성, 이주연(2009). 수용·표현어휘력검사(REVT). 서울: 서울장애인종합복지관.

신현정(2003). 인터넷을 이용하여 작성된 범주규준의 타당도 연구. 한국 인지 및 생물 심리학회지, 15(2), 303-346.

배세령, 하지완, 구민모, 황유미, 편성범(2016). 말소리장애아동의 새로운 음운표상 형성 능력. Communication Sciences \& Disorders, 21(1), 24-36. 임호찬(2004). 한국판 레이븐 지능검사(K-CPM). 서울: 한국가이던스.

\section{ORCID}

